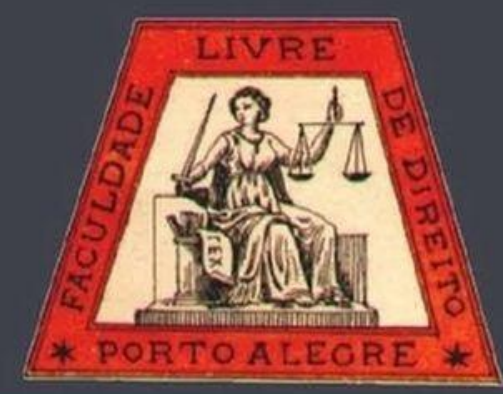

\title{
Kelsen entre a construção da moldura e o conteúdo da norma fundamental
}

Kelsen between framework construction and the content of basic norm

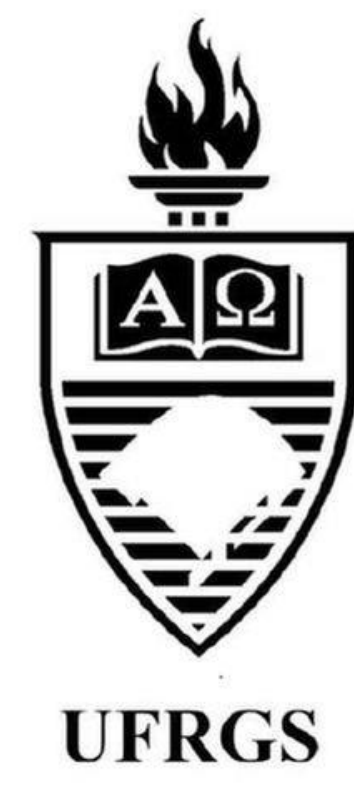

\section{Helder Gonçalves Lima}

Universidade Federal de Alagoas

Adrualdo Lima Catão

Universidade Federal de Alagoas 


\title{
Kelsen entre a construção da moldura e o conteúdo da norma fundamental
}

\author{
Kelsen between framework construction and the content of basic norm
}

Helder Gonçalves Lima*

Adrualdo Lima Catão ${ }^{* *}$

\section{REFERÊNCIA}

LIMA, Helder Gonçalves; CATÃO, Adrualdo Lima. Kelsen entre a construção da moldura e o conteúdo da norma fundamental. Revista da Faculdade de Direito da UFRGS, Porto Alegre, n. 40, p. 243-255, ago. 2019.

\section{RESUMO}

O presente tem como finalidade analisar a obra "Teoria Pura do Direito", de Hans Kelsen, numa visão mais contemporânea, mediante uma análise do propósito encampado pelo autor de Viena e que, por vezes, é pouco compreendido no cenário jurídico brasileiro. Para tanto, o estudo compreenderá conceitos firmados pelo autor, numa busca por explicar os conceitos que ensinou sobre a moldura e a questão da norma fundamental. Assim, a intenção é disseminar os estudos de Kelsen na perspectiva atual, haja vista ter influência não somente no seio acadêmico, mas também na jurisprudência por meio de sua visão de aplicação do direito.

\section{PALAVRAS-CHAVE}

Teoria do Direito. Hans Kelsen. Interpretação. Aplicação. Norma fundamental.

\section{ABSTRACT}

The purpose of this paper is to analyze Hans Kelsen's book "Pure Theory of Law", in a more modern way, through an analysis of the purpose of the Vienna author and which is sometimes little understood in the Brazilian legal context. For this, the study will include concepts signed by the author, in a search to explain the concepts he taught about the framework and the question of the basic norm. Thus, the intention is to disseminate Kelsen's studies in the current perspective, since it has influenced not only in the academic sphere but also in court decisions through his vision of the application of law.

\section{KEYWORDS}

Legal theory. Hans Kelsen. Interpretation. Application. Basic norm.

\section{SUMÁRIO}

Introdução. 1 Contexto histórico da Teoria pura do Direito. $1.1 \mathrm{O}$ ato e seu(s) sentido(s). 1.2 Ato de vontade e produção normativa. 2 A norma hipotética fundamental. 2.1 A não-positividade da norma fundamental ou sobre o porquê de a norma fundamental não ser imanente ou transcendente ao Direito Positivo. 2.2 O problema do conteúdo da norma fundamental ou sobre a dinâmica do Direito como decorrência da neutralidade desta norma. 2.2.1 Grundnorm, estática e dinâmica normativa. $3 \mathrm{O}$ papel da interpretação na mutabilidade do Direito. 3.1 Indeterminação do ato de aplicação do Direito. 3.2 Sobre a construção da moldura. Considerações finais. Referências.

\footnotetext{
* Professor da Faculdade de Direito da Universidade Federal de Alagoas (UFAL). Atualmente é o Presidente da empresa pública Alagoas Ativos.

* Professor adjunto da Universidade Federal de Alagoas, professor do Centro Universitário CESMAC, professor titular do Centro Universitário Tiradentes e Secretário Executivo do Gabinete Civil do Governo do Estado de Alagoas.
} 


\section{INTRODUÇÃO}

Esse estudo deita raízes, basicamente, na Teoria Pura do Direito - obra máxima de Kelsen, cujos instrumentais teóricos ainda hoje fundamentam boa parte da Teoria Geral do Direito e povoam o imaginário da dogmática jurídica. Sua importância é inegável.

Ocorre que, malgrado seja sempre citado, Kelsen pode ser considerado um autor pouco compreendido. Conceitos fundamentais de sua teoria, como o supino conceito de norma fundamental, não são tomados em toda a sua complexidade. O mesmo se dá com a questão da moldura normativa. Em relação a este último conceito, pensamos poder ser emprestada ao mesmo uma leitura mais moderna, mas ainda assim dentro das balizas teoréticas encampadas pelo autor de Viena.

Com efeito, todo o texto que se segue se presta a analisar os conceitos mencionados acima com estribo nos elementos colhidos na própria teoria kelseniana. Valemo-nos de seu vocabulário próprio e, para além disso, de todos os demais conceitos que subjazem a esta rica teoria para lograr surpreender, ao final, o conteúdo da norma fundamental e definir como se dá a construção da moldura.

\section{O CONFLITO E A PERSPECTIVA RETRIBUTIVA DA PRÁXIS}

No mesmo berço histórico se encontram o Estado Moderno e a concepção Positivista do Direito, em detrimento da concepção jusnaturalista. No Estado moderno surge o monopólio da produção do Direito (e da violência). Assim é que o Direito passa a ser unicamente aquele produzido pelo Estado. Com efeito, esta não é uma conceituação geral de
Direito, mas apenas uma definição baseada num contexto histórico ${ }^{1}$.

Nesse diapasão, Kelsen formula sua Teoria Pura do Direito, num esforço de apartar do objeto de conhecimento tudo aquilo que não é especificamente jurídico. Afasta-se, assim, de toda espécie de concepção do Direito baseada na ideologia, na metafísica ou no transcendentalismo - tão disseminadas nesse período histórico.

Realizada essa breve introdução, analisemos alguns conceitos basilares da teoria kelseniana a fim de melhor entendermos os pressupostos sobre os quais deita raízes a teoria pura.

\section{$1.1 \mathrm{O}$ ato e seu(s) sentido(s)}

Kelsen afirma existir em todo fato que consideramos jurídico (como um contrato ou uma sentença) um sentido dúplice ou bipolar. Isto porque implica na percepção de um ato (como conduta humana) posto no espaço e no tempo e, também, de sua significância jurídica, i.e., o significado que o tal ato tem do ponto de vista do Direito ${ }^{2}$.

No que concerne ao ato praticado por um sujeito, pode-se dizer deste (ato) que contém um sentido ou direção. Quem pratica determinado ato, empresta-lhe um sentido. Daí seu caráter subjetivo. Quanto a este mesmo ato, pode o Direito, de sua perspectiva, empregar-lhe um sentido objetivo, o qual coincidirá, ou não, com o sentido posto pelo sujeito.

Há se perguntar o que orienta a perspectiva do Direito sobre o sentido de um ato. Para a teoria de Kelsen, não se levará em conta o ato em sua integridade constitutiva empiricamente verificada. Assim como tido pela

\footnotetext{
${ }^{1}$ BOBBIO, Norberto. O Positivismo Jurídico: lições de filosofia do Direito. São Paulo: Ícone, 1995. p. 26-29.

${ }^{2}$ KELSEN, Hans. Teoria Pura do Direito. (Tradução de João Batista Machado). $6^{\mathrm{a}}$ ed., São Paulo: Martins Fontes, 1999. p. 2.
} 
causalidade natural, $\mathrm{o}$ ato não interessa ao Direito. A sua significação jurídica específica, que independe de seu sentido subjetivo, é posta através de uma norma jurídica. Dessa forma, a norma funcionará como verdadeiro esquema interpretativo em relação ao fato, emprestando-o um sentido objetivo.

É como se a norma funcionasse como um filtro que eliminasse do fato a sua porção causal (natural), tornando-o, assim, fato jurídico. É dizer: emprestando-lhe significação jurídica. $\mathrm{O}$ tornar-se fato jurídico, porém, não desconstrói aquela parcela causal do fato (ato), que subsiste como sentido subjetivo. Destarte, um mesmo ato deterá um sentido subjetivo (do ponto de vista do sujeito, por assim dizer) e um outro, alcançado através de uma interpretação calcada na norma jurídica que se refere a ele, um sentido objetivo (ponto de vista do Direito).

Se o ato de um sujeito exprime um dever-ser em seu sentido subjetivo (ato de vontade dirigido ao regramento da conduta de outrem), e não é ao mesmo dado qualquer sentido objetivo pela norma, esse dever-ser não será jurídico. O que torna o dever-ser um deverser jurídico é a norma que dá sentido objetivo ao ato. Obtempere-se, por oportuno, que com este (ato) aquela (norma jurídica) não se confunde. Uma coisa é o ato a quem a norma dá sentido objetivo, outra, o ato de vontade que tem seu sentido constituído por aquela. Destarte, somente o dever-ser com sentido objetivo é norma válida. A norma se encontra no plano do dever-ser jurídico e o ato de vontade no universo do ser.

\subsection{Ato de vontade e produção normativa}

O Direito é um plexo de normas voltadas para o disciplinamento da conduta humana. As normas então definem como o homem deve se portar, ou seja, como algo deve ser no plano das relações interpessoais. Temos assim o ato de vontade dirigido à conduta de outrem, no sentido de determinar como deve-ser. Quando um ato exprime a vontade (de um indivíduo ou de um grupo deles) de que um dado indivíduo se porte de certo modo, permitindo, obrigando ou proibindo algo, haverá aí uma norma posta, constituinte do sentido objetivo deste ato.

O querer, o elemento volitivo do ato, encontra-se no plano psicofísico, ou seja, no mundo do ser. O sentido objetivo deste ato, que consubstancia a norma, no plano do dever-ser. Nesses termos, o objeto do ato (a conduta em geral) intencionalmente é posto em termos de algo que deve-ser e não de algo que é. A norma é o sentido específico do ato volitivo dirigido à conduta humana e, por isso, não se confunde com o ato volitivo a que ela (norma) empresta sentido objetivo. A norma é dever-ser e o ato de vontade é ser.

Mesmo quando a norma é descumprida, é dizer, mesmo quando a conduta determinada no consequente da norma não se verifica no mundo fenomênico, não se diz que o dever-ser perdeu o sentido. O sentido objetivo do ato permanece e seu objeto continua como dever-ser. Outrossim, ainda nos casos em que tal dever-ser seja efetivamente verificado no plano da realidade objetal, não haverá se falar que este é. Será sempre dever-ser. O plano normativo e o plano real são distintos, e não há passagem de um para o outro sem solução de continuidade.

De bom alvitre salientar, ainda, que o sentido objetivo de um ato de vontade, sendo norma, é posto por uma outra norma ${ }^{3}$ que lhe é superior. Sim, porque na teoria kelseniana só uma norma põe outra norma no sistema. Toda norma apreende sua validade de uma norma distinta e que em relação a ela é superior, até a Norma Fundamental - fundamento último de validade de um ordenamento jurídico dado.

\footnotetext{
${ }^{3}$ Sobre a auto-produção e auto-regulação do Direito na perspectiva kelseniana versaremos mais detidamente em
} momento ulterior e oportuno. 
A esse passo fica clara a relação havida entre ato de vontade humana e produção normativa na concepção kelseniana. Com efeito, os atos de vontade são condição indispensável para a existência de normas jurídicas. As normas são, em derradeira análise, o sentido objetivo atribuído ao ato volitivo. Só com o fato do querer empírico de um indivíduo, submetido ao processo definido por outras normas, pode nascer norma jurídica como sentido objetivo deste ato humano.

Contudo, uma coisa é a dependência que existe entre a sua existência (como norma) e $\mathrm{o}$ ato de querer humano. Uma outra é sua validade. A validade é condição de pertinência ao sistema de que a norma faz parte, e nesse sentido independe daquele ato de vontade ${ }^{4}$. Esta é, enfim, a relação entre conteúdo objetivo e ato de vontade. A validade exsurge como qualidade própria do dever-ser, do sistema de normas jurídicas válidas, por isso não se encontra vinculada ao ato de querer humano - encontrado no mundo do ser.

Mas não é só isso. Nas relações entre os atos e as normas há se sublinhar, ainda, a circunstância de que, na dinâmica de produção normativa, onde se diz que norma põe norma, na verdade ocorre de uma norma superior estipular um ato produtor de outras normas jurídicas. Assim é que entre uma norma superior e outra que lhe é inferior, porquanto fora produzida de acordo com aquela, há um ato produtor juridicamente qualificado assim. Por outros torneios: entre N' e N", existe um ato de vontade (logo, humano) previsto normativamente.

Sobreleva-se, pois, a inferência de que a positivação do Direito depende do ato de vontade. O que equivale a dizer que uma norma, por si só, não põe a outra sem um ato produtor que as intermedeie. Não fosse desse modo e

\footnotetext{
${ }^{4}$ VILANOVA, Lourival. Teoria da Norma Fundamental. In: Escritos Jurídicos e Filosóficos. São Paulo: Axis Mundi: Ibet, 2003. Volume I. p. 325.
}

estaríamos frente a um modo de produção inferencial-dedutivo do Direito Positivo, como sói ocorrer nas sendas do jusnaturalismo e outros sistemas estáticos.

\section{A NORMA HIPOTÉTICA FUNDAMENTAL}

Conforme dito alhures, o fundamento de validade de uma norma jurídica só pode ser uma outra norma jurídica. Assim, uma norma qualquer toma sua validade em uma outra que lhe é superior, está em outra ainda, e assim por diante. Mas esse raciocínio não pode se perder num regressus ad infinitum, por uma necessidade epistemológica.

Dentro de um sistema de Direito positivo a norma positiva que se encontra no escalão mais alto é a Constituição. Mas o que dá validade a esta Constituição? Não pode haver uma outra norma positiva que lhe dê validade. A Constituição, por inferência lógica, deve ser a última norma positiva do sistema. O suposto de validade da Constituição, portanto, está fora do sistema jurídico positivo.

A resposta encontrada por Kelsen foi afirmar um axioma: o fundamento último de validade de qualquer ordem jurídica é uma norma hipotética fundamental (Grundnorm), pressuposto lógico de validade do sistema. Esta seria a norma última a validar todo o sistema e garantir, ato contínuo, sua unidade e seu fechamento. Logo, o Direito se fundamenta em si mesmo ${ }^{5}$. É dizer: o sistema jurídico começa e

\footnotetext{
${ }^{5}$ Acerca da auto-referência ou auto-fundamento do Direito Positivo na teoria kelseniana, que se traduz na sua própria regulação quanto a sua produção e aplicação, ver: KELSEN, Teoria Pura do Direito, pp. 80; 257; 263 e ao longo de toda a obra deste autor. Também: VILANOVA, op. cit., p. 312 e ss. Com isso, Kelsen quer deixar claro que o Direito se auto-regula independentemente do mundo do ser, pois só norma disciplina outra norma do sistema. Entretanto, é curioso observar em sua teoria a afirmação acerca de que o fundamento de validade das normas, e mesmo da ordem jurídica, é a norma fundamental, mas que a eficácia social, duma e de outra, é condição de validade
} 
termina com normas jurídicas, que regulam e realizam sua própria (re)produção.

\subsection{A não-positividade da norma fundamental ou} sobre o porquê de a norma fundamental não ser imanente ou transcendente ao Direito Positivo

De acordo com o que fora exposto no subitem 1.1.2, norma positiva é aquela que deriva de um ato de criação (produção) dirigido por uma outra norma do sistema. Logo, entre uma e outra norma interpõe-se um ato (de vontade). Este ato é vital para o movimento do Direito, afinal suas normas não derivam por dedução umas das outras.

Mas qual ato de vontade pôs a norma fundamental?

A resposta só pode ser nenhum. Assim está em que a norma fundamental não é norma de Direito positivo. Afinal, em havendo um ato de vontade que crie a norma fundamental, teria de haver uma norma ponente deste mesmo ato de produção, que por sua vez estaria vinculada a uma outra (norma) que lhe seria superior. A regressão seria, vez mais, ilimitada. Com supedâneo nisso, a teoria kelseniana afirma o caráter de pressuposto gnosiológico ${ }^{6}$ da

de ambas. Reconhece, enfim, que a eficácia (plano do ser) não se confunde com validade (plano do dever-ser), intentando, assim, deixar claro o fechamento do sistema. Ocorre que, debalde afirme tal fechamento, aliado a circunstância de que a norma fundamental empresta validade a todo esse sistema, a eficácia aparece como condição de validade da norma jurídica. Isto porque, afirma Kelsen, sem uma eficácia (social) mínima a norma se torna, de pronto, inválida (Kelsen, Teoria Pura do Direito. pp. 235 e ss.). Ora, prelecionar isso é de certo modo a negação da premissa de que uma norma só toma validade em uma outra superior. Com efeito, não sendo " $a$ falta de eficácia mínima" o antecedente de uma norma superior - e não é -, a invalidade em casos assim se deverá exclusivamente a uma causa do mundo do ser, malgrado seja a invalidação de uma norma um "efeito jurídico", porquanto importa em sua retirada do sistema jurídico. Isto é o mesmo que afirmar que o ser define o dever-ser. $\mathrm{O}$ factual define o deôntico. Onde está a auto-regulação do Direito, então?

${ }^{6}$ Estamos de acordo com Lourival Vilanova quando este afiança que "em rigor, indo ao nível da norma
Grundnorm. Ante a premissa de que um ato normado é ponente de norma positiva, fica claro que a norma fundamental não é norma positiva, mas axioma fundamental do sistema de Kelsen garantidor do fechamento operativo do sistema.

Pois bem. Não sendo a norma fundamental norma positiva, temos que esta não pode ser imanente ao sistema positivo, posto que não se encontra no seu interior. A norma fundamental também não encerra um valor supremo para o sistema de Direito Positivo, algo que transcenda o próprio ordenamento. É dizer: não funciona a norma fundamental como uma norma básica cujo conteúdo material é um valor absoluto vinculativo do sistema normativo para o qual se direciona ${ }^{7}$. É por isso que se diz que norma fundamental também não é, nesse sentido, transcendente ao Direito Positivo.

O que não podemos perder de vista, porém, é o caráter deôntico ínsito a norma fundamental. Sim, porque toda norma provém de norma. A norma é o início e o fim do sistema jurídico, para Kelsen. O fundamento base, o elemento mínimo do sistema normativo é a norma. Assim é que a norma fundamental possui natureza deôntica. Não poderia ser diferente, ou resvalaríamos para a sociologia jurídica ou o transcendentalismo que Kelsen visou rebater.

O dever-ser é functor relacional ${ }^{8}$ dirigido aos fatos sociais, às condutas. A validade é qualidade do dever-ser, e "a validade

fundamental ele (o jurista) vai além do ordenamento positivo e vai além do recinto onde se move a Ciência-doDireito" (grifo do original). (VILANOVA, Lourival. Teoria da Norma Fundamental. In: VILANOVA, Lourival. Escritos Jurídicos e Filosóficos. São Paulo: Axis Mundi: Ibet, 2003. Volume I. p. 320.) Nesse diapasão, Vilanova afirma, ainda, que a teoria da Grundnorm está no plano de uma teoria da ciência do Direito, o que nos autoriza a dizer, seria ela uma metateoria. (Ibid., p. 306 e 320.)

${ }^{7}$ Para mais nesse sentido, consultar: Kelsen, Teoria Pura do Direito, p. 225; VILANOVA, op. cit., p. 304-305.

${ }^{8}$ Id. As Estruturas Lógicas e o Sistema do Direito Positivo. São Paulo: Max Limonad, 1997. p. 75 e ss. 
(à parte outros sentidos do termo) de um deverser somente em outro dever se acha"9.

Afigura-se-nos, pois, imperioso afirmar que a norma fundamental é o fundamento de validade de todo ordenamento jurídico positivo, sem ser ela mesma norma positiva. A Grundnorm confere unidade à multiplicidade do sistema normativo do Direito.

2.2 O problema do conteúdo da norma fundamental ou sobre a dinâmica do Direito como decorrência da neutralidade desta norma

Kelsen, ao criar sua teoria pura, visava a todo custo se afastar dos postulados do jusnaturalismo e da intromissão de considerações de ordem sociológica e ideológica nos conceitos jurídicos. Imbuído desse afã, procedeu a uma purificação metodológica para além dos planos lógico e epistemológico (na esteira de Husserl e, antes dele, Kant). Pretendeu isolar a proposição jurídica. Tanto na direção dos valores absolutos próprios do Direito Natural, como do substrato empírico-social donde se abebera o Direito Positivo. Isola-se a proposição jurídica dos valores não positivados pelo sistema do Direito e, da mesma sorte, do universo social em que o Direito vale e foi posto (positivado) ${ }^{10}$.

Resulta disso que o Direito Positivo duma sociedade historicamente dada é o objeto da Ciência do Direito; o Direito é norma, e não fato (como faziam crer as teorias sociológicas do Direito); e, por fim, o dever-ser é functor relacional dos objetos da experiência tidos normativamente por supostos (antecedentes) normativos, e suas respectivas consequências também postas pela norma em relação de implicação lógica (não causal). É essa noção de

\footnotetext{
${ }^{9}$ VILANOVA, Lourival. Teoria da Norma Fundamental. In: VILANOVA, Lourival. Escritos Jurídicos e Filosóficos. São Paulo: Axis Mundi: Ibet, 2003. Volume I. p. 321.

${ }_{10}$ Acerca dessas e outras considerações desse capítulo, consulte-se ibidem, p. 314.
}

imputabilidade um dos grandes ganhos da purificação de Kelsen. Não cabe, contudo, olvidar que o deôntico diz, sempre, com valores. Somente por meio de abstração lógica colocamos entre parênteses metodológicos o dever-ser para declinar o que de valioso ele implica. As condutas, pois, são direcionadas no sentido dos valores que a sociedade quer ver implantados. Porém, o Direito toma estes valores positivados sem emitir qualquer espécie de juízo de sobre valoração.

Calha, nesse ponto, afirmar a ausência de conteúdo axiológico da norma fundamental, que não põe no sistema jurídico qualquer valor transcendental. É dizer: a norma fundamental prescinde de conteúdo axiológico. Com isso queremos significar que a norma fundamental é neutra do ponto de vista valorativo. Para além do Direito positivo está a norma fundamental, e para aquém desta estão os dados axiológicos.

Obtempere-se, por oportuno, que, malgrado o afiançado linhas acima, a norma fundamental não se reduz a uma mera fórmula lógica, como que matemática, fadada a ser absolutamente estéril de conteúdo.

A norma fundamental tem uma função lógica. Ela se dirige a um objeto. Corresponde objetivamente ao fato criador da ordem jurídica. Afinal, para que a norma incida, deve haver um suporte fático. É dizer: a norma fundamental adquire, num dado momento, um conteúdo relativo a este suporte fático fundamental, por assim dizer. A Grundnorm, pois, saca seu conteúdo de um dado objetivo - o fato empírico criador do Direito Positivo historicamente considerado.

Afigura-se-nos, assim, a posição precedente da norma fundamental a respeito da validade na pirâmide do sistema jurídico e, em contra-nota, a circunstância de que relativamente ao conteúdo ela é a posteriori. Mas essa adjudicação de conteúdo para a norma fundamental de um sistema não é arbitrária, ou 
mesmo referida a algo transcendental, mas se encontra, sim, vinculada a um dado-de-fato histórico posto pela experiência ${ }^{11}$.

Pois bem. O dado-de-fato oferecido pela experiência do real é o sentido subjetivo de um ato (o ato constituinte), que interpretado pelo seu sentido objetivo inaugura um sistema jurídico. E esse seu sentido objetivo, aqui, é dado pela norma fundamental. Assim é que a norma fundamental sempre se refere a uma Constituição (no sentido de norma máxima dum sistema de Direito Positivo) concreta, historicamente dada. Somente ao se interpretar o sentido objetivo do ato constituinte - através da norma fundamental, confere-se validade a um sistema normativo, indo desde a Constituição até os demais dados jurídicos derivados daí no processo de positivação. Por outros torneios: somente quando se pressupõe a norma fundamental e se interpreta o conteúdo subjetivo do ato constituinte como seu sentido objetivo é que se toma o Direito positivado como sistema de normas válidas.

Note-se que na pressuposição da norma fundamental, enquanto elemento a priori de validade, não se afirma qualquer conteúdo ou valor relativo a ela. Contudo, no momento em que essa (norma fundamental) se refere a uma Constituição concreta, a mesma assume um conteúdo, que se instaura, portanto, a posteriori. Sublinhe-se que, nestas sendas de Teoria Geral do Direito, não há se falar em sucessão cronológica, mas meramente lógica. A norma fundamental assume um significado (conteúdo), que não é outro, senão, a atribuição de poder para que os órgãos constitucionais possam criar normas válidas a que seus destinatários devem obedecer $^{12}$, ou seja, deve-se obedecer à

\footnotetext{
${ }^{11}$ Nesse sentido: KELSEN, Hans. Teoria Pura do Direito. (Tradução de João Batista Machado). $6^{\mathrm{a}}$ ed., São Paulo: Martins Fontes, 1999. p. 225; VILANOVA, Lourival. Teoria da Norma Fundamental. In: VILANOVA, Lourival. Escritos Jurídicos e Filosóficos. São Paulo: Axis Mundi: Ibet, 2003. Volume I. p. 316 a 318.

${ }^{12}$ BOBBIO, Norberto. Teoria do Ordenamento Jurídico.
} $10^{\text {a }}$ ed., Brasília: Editora UNB, 1999. p. 58 e ss.
Constituição

concretamente considerada

e haurida sob o pálio do poder constituinte originário.

A cada Constituição concreta equivale, portanto, uma norma fundamental específica ${ }^{13}$, pelo menos quanto ao seu conteúdo objetivamente avaliado. No que pese ser irrelevante o conteúdo das ordens jurídicas estabelecidas sob o manto da norma fundamental. Sobre ser irrelevante o conteúdo de um dado ordenamento, diz-se que este não é definido, ou dedutível, do conteúdo mesmo da norma fundamental. Logo, se num primeiro momento a Grundnorm não tem conteúdo e depois o adquire, jamais será no sentido de se lhe emprestar cunho axiológico vinculativo, ou transcendental, sob pena de restar desnaturado o modelo teórico de matriz kelseniana.

Dessa neutralidade de conteúdo relativa à norma fundamental resultam dois aspectos fundamentais para a Teoria Pura do Direito: a) o que define a validade das normas do sistema é a forma como são produzidas, e não seu conteúdo; e b) as normas desse mesmo sistema são postas por atos de vontade com conteúdo objetivo, logo, não são hauridas sob os auspícios de jogos de inferência dedutiva.

Com efeito, na ausência de conteúdo axiológico na norma fundamental, o que define a validade das normas do sistema é a maneira como são postas no ordenamento, i.e., válidas são as normas que obedecem ao procedimento prescrito pelas normas superiores no interior do sistema jurídico. Ademais, positiva é a norma proveniente de um ato de produção que se interpõe entre duas normas: a superior e a

\footnotetext{
${ }^{13}$ Estudando as constituições compreendidas no período de 1891 a 1946, Lourival Vilanova preceitua que todas elas advieram de uma revolução política, mas também jurídica, na medida em que importaram na "quebra da continuidade constitucional. Consequentemente, normas fundamentais diferentes". (VILANOVA, Lourival. Teoria Jurídica da Revolução. In: VILANOVA, Lourival. Escritos Jurídicos e Filosóficos. São Paulo: Axis Mundi: Ibet, 2003. p. 275276.)
} 
inferior (norma criada). Na falta de um valor superior, transcendental, posto pela norma fundamental, somente este ato de criação com conteúdo objetivo põe norma válida no sistema, qualquer que seja seu conteúdo, na medida em que obedecido o comando de tais normas superiores.

\subsubsection{Grundnorm, estática e dinâmica normativa}

Ao longo desse trabalho vários traços distintivos do sistema dinâmico foram gizados, e também alguns que dizem mais de perto com o sistema estático de normas. Não sobeja esgrimir aqui mais alguns poucos argumentos para que esta distinção reste flagrante.

Em sistemas como o do Direito Natural, há um valor supremo, transcendental, fundamento último do poder, a informar todo o sistema de maneira inelutável, seja a vontade divina, seja a razão humana, ou ainda a convenção originária a representar o papel de norma fundamental ${ }^{14}$. Em sistemas que tais, todas as normas derivam, por inferência lógicodedutiva, da norma fundamental - prenhe de conteúdo a priori. Não há ato de criação relevante nesse modelo. Tudo é deduzido da norma fundamental e está em absoluta consonância com esta, que assume o caráter da imutabilidade. Daí dizer-se que estes são sistemas normativos estáticos.

N'outro diapasão encontram-se os sistemas dinâmicos, erigidos sob as hostes de uma norma fundamental neutra axiologicamente, com todas as consequências que demonstramos ao longo do presente, e que não cuidaremos aqui de repisar, a fim de não cansar o leitor. Vale, contudo, relembrar que nesse sistema uma norma

\footnotetext{
${ }^{14}$ Para mais detalhes sobre o assunto recomendamos a leitura de: BOBBIO, Norberto. O Positivismo Jurídico: lições de filosofia do Direito. São Paulo: Ícone, 1995. passim. Id. Teoria do Ordenamento Jurídico. $10^{\mathrm{a}}$ ed., Brasília: Editora UNB, 1999. p. 64 e ss. Para ficar nas obras do maior comentador de Kelsen.
}

posta é uma norma fruto de um ato de criação regulado por uma outra norma, que em relação à norma criada é superior.

$\mathrm{O}$ que se quer dizer aqui é que o conteúdo, mesmo das normas inferiores, não se encontra vinculado visceralmente ao conteúdo da norma que lhe é superior ${ }^{15}$. Em verdade, ao longo de todo o percurso de produção normativa, ou de positivação do Direito, há sempre - por menor que seja, um acréscimo em relação ao conteúdo das normas predecessoras. E isso desde a norma fundamental até a norma de máxima concreção (norma individual e concreta), passando pela Constituição ${ }^{16}$. O que há de fundamental é que não há determinação absoluta de conteúdo normativo nesses modelos dinâmicos, ao revés do que se dá nos estáticos.

\section{O PAPEL DA INTERPRETAÇÃO NA MUTABILIDADE DO DIREITO}

Já vimos que as normas jurídicas podem encerrar os mais variados conteúdos normativos, dada a ausência de predeterminação transcendental de conteúdo por parte da norma fundamental. Com efeito, os ordenamentos jurídicos guardam, cada um, sua identidade, não se cogitando deles em termos axiológicos.

Nesse contexto, Kelsen observa duas espécies de interpretação do texto jurídico: a interpretação realizada pelos órgãos jurídicos definidos pelo sistema; e a interpretação colhida pelos demais intérpretes, sobretudo pela Ciência Jurídica. Aquela primeira, Kelsen denomina de

\footnotetext{
${ }^{15}$ Sem prejuízo das normas que detêm a chamada relação de hierarquia material em relação a que lhe é inferior, ou seja, aquelas normas que definem de certo modo o conteúdo que a norma inferior deverá encerrar. Mas esta é apenas uma das espécies normativas dentro de um sistema dinâmico. O importante é que o princípio dinâmico não diz com vinculação de conteúdo inexorável, como a do sistema estático.

${ }^{16}$ No mesmo sentido a doutrina de Vilanova, em Teoria da Norma Fundamental. In: VILANOVA, Lourival. Escritos Jurídicos e Filosóficos. São Paulo: Axis Mundi: Ibet, 2003. Volume I. p. 316.
} 
interpretação autêntica do Direito. É sobre ela que vamos tratar agora.

3.1 Indeterminação do ato de aplicação do Direito

Para Kelsen a norma superior determina a produção da norma inferior e, em derradeira instância e de certo modo, a aplicação final do Direito, ou sua execução, realizada pelos tribunais (intérpretes autênticos). A determinação imposta pela norma superior atinge a forma como a norma inferior deve ser produzida e, eventualmente, seu conteúdo. Entretanto, essa determinação nunca é completa. Há sempre uma margem de liberdade nos atos inferiores, em maior ou menor grau, de maneira que a norma superior faz as vezes de uma moldura que deve ser preenchida por aquele ato. Assim é que a criação e a aplicação (execução) do Direito são só em parte determinadas por este $^{17}$. O processo de determinação parte da norma geral e abstrata até atingir a norma individual e concreta, no processo seriado e gradual de determinação do Direito.

Outrossim, Kelsen em sua teoria pura afirma a necessidade de o texto jurídico ser interpretado, pois encerra diversas interpretações possíveis, por conta da pluralidade de sentido das palavras $^{18}$, que não possuem um sentido em si mesmas. É nesse jaez que Kelsen vai dizer que o intérprete do Direito estará diante de uma multiplicidade de sentidos possíveis ao aplicálo ${ }^{19}$.

17 Sobre as considerações tecidas neste tópico ver: KELSEN, Hans. Teoria Pura do Direito. (Tradução de João Batista Machado). $6^{\mathrm{a}}$ ed., São Paulo: Martins Fontes, 1999. p. 387 e ss.

${ }^{18}$ Vale o registro de que esse desapego às concepções metafísico-essencialistas é próprio do movimento filosófico do qual Kelsen participou, liderado por Moritz Schlick e conhecido por "Círculo de Viena", ali pelos idos do início do século XX, e que fundou o positivismo lógico ou Neo-positivismo.

${ }^{19}$ Alguns autores criticam a vacilação de Kelsen quanto a afirmação da indeterminação do Direito. Questiona-se se
Não sobeja dizer sobre a existência de uma distinção havida entre texto normativo e norma jurídica que subjaz a teoria kelseniana ${ }^{20}$, ainda que se possa fazer uma crítica contundente a ela quando esta se refere a uma busca da "vontade do legislador". Contudo, o importante é que Kelsen reconhece o caráter jurídico de qualquer ato de aplicação que se encontre dentro das possibilidades interpretativas que compõem a moldura.

\subsection{Sobre a construção da moldura}

Com efeito, um dos pontos basilares, e um dos grandes passos dados no sentido do progresso da ciência jurídica, é o reconhecimento de Kelsen, em seus termos, da dualidade texto e norma jurídica (em sentido estrito, acresceríamos de mão própria). Pensamos que é possível traduzir a linguagem de Kelsen - sem alterar seu sentido original - para dizer que está ali a seguinte ideia: o texto, sendo expressão empiricamente objetivada, implica numa pluralidade de sentidos possíveis - a moldura. Sublinhe-se, por oportuno, que não são todas as interpretações possíveis a partir do texto que estão dentro da moldura, mas tão só aquelas em consonância com o sistema. As demais estão simplesmente fora da moldura.

Assim é que se nos afigura como construtiva/constitutiva da moldura a atividade do intérprete. Com isso queremos dizer que a moldura não é posta pela norma jurídica, ou pelo sistema, mas a partir dele, e pelo intérprete, enfim. Ela (a moldura) não já está lá, mas é posta pelo ato interpretativo do sujeito cognoscente, no caso órgão jurídico competente. Por outros torneios: a moldura é construída pelo intérprete,

ela seria mesmo inarredável ou se haveria casos em que a lei seria clara o suficiente para externar seu conteúdo e a vontade do legislador. Para mais detalhes ver: VIDAL, Isabel Lifante. La Interpretación Jurídica em la Teoria del Derecho Contemporânea. Madrid: Centro de estudos políticos y consttucionales, 1999. p. 70 e ss.

${ }^{20}$ KELSEN, op. cit., p. 389-390. 
e não posta pelo Direito, como se o fizesse independentemente daquele (intérprete).

Dentro da moldura se encontram as interpretações possíveis (normas válidas, diríamos) construídas a partir do texto positivo. Estas interpretações possíveis se traduzem, no ato de aplicação do Direito, em possibilidades de aplicação. É dizer: o órgão competente poderá aplicar ao caso concreto qualquer das interpretações possíveis da norma, e que se encontram, pois, compreendidas dentro da moldura normativa. Não há se olvidar, nesse diapasão, a função criadora desses órgãos, que não é, pois, meramente declaratória ${ }^{21}$, malgrado seja essa função limitada pelo próprio sistema, que confere validade às normas. Enfim, não há só uma interpretação possível, como se fosse a interpretação correta, o que revelaria uma concepção essencialista com a qual, como visto, o pensamento do mestre de Viena não se compadece.

A necessidade da interpretação repousa, pois, nessa inexistência de uma interpretação única, correta - o que só seria possível no caso de uma norma fundamental com conteúdo axiológico transcendental e, por conseguinte, vinculativo das demais normas desse sistema, que derivariam dela por dedução. No Direito positivo há inúmeras possibilidades interpretativas, diversos são, pois, os conteúdos normativos e as possibilidades de aplicação concreta da norma.

Então é assim: há o texto positivo, e a partir dele o intérprete constrói a moldura (de acordo com os critérios de validade do sistema) onde estão contidas as possibilidades (interpretativas) de aplicação; e desse ponto em diante o Direito positivo já não fornece qualquer critério para a escolha da decisão a ser aplicada concretamente. Essa decisão/escolha entre as interpretações contidas na moldura é, nesses termos, um problema político. A decisão sobre a norma a aplicar é livre e cabe ao órgão competente (juiz ou tribunal). Uma vez feita esta escolha política, eis a norma individual e concreta posta no sistema, em seu continuum reprodutivo.

\section{CONCLUSÃO}

A ausência de conteúdo pré-determinado por uma norma fundamental axiologicamente neutra implica em uma dupla indeterminação normativa: a indeterminação quanto ao conteúdo da norma jurídica e da própria ordem normativa como um todo; e a indeterminação da norma (como significação) a ser aplicada, dentro das múltiplas significações construídas a partir do texto positivo - no que pese o fato de que a escolha pela aplicação de uma das significações não exclui as demais, nem mesmo a possibilidade de sua aplicação em outros casos, ou até no mesmo, por um órgão decisional superior. O Direito para Kelsen é mutável, dinâmico, contingente, enfim.

\footnotetext{
${ }^{21}$ KELSEN, Hans. Teoria Pura do Direito. (Tradução de João Batista Machado). $6^{\mathrm{a}}$ ed., São Paulo: Martins Fontes,
} 1999. p. 264, 265, 268 e 393. 


\section{REFERÊNCIAS}

BOBBIO, Norberto. O Positivismo Jurídico: lições de filosofia do Direito. São Paulo: Ícone, 1995.

BOBBIO, Norberto. Teoria do Ordenamento Jurídico. 10ª ed., Brasília: Editora UNB, 1999.

KELSEN, Hans. Teoria Pura do Direito. (Tradução de João Batista Machado). $6^{\text {a }}$ ed., São Paulo: Martins Fontes, 1999.

VIDAL, Isabel Lifante. La Interpretación Jurídica em la Teoria del Derecho Contemporânea. Madrid: Centro de estudos políticos y consttucionales, 1999.

VILANOVA, Lourival. As Estruturas Lógicas e o Sistema do Direito Positivo. São Paulo: Max Limonad, 1997.

VILANOVA, Lourival. Escritos Jurídicos e Filosóficos. São Paulo: Axis Mundi: Ibet, 2003. Volume I.

Recebido em: 09/07/2018

Aceito em: 07/08/2019 
